\title{
Individualized and multidisciplinary approach of syncope in the elderly: a case report
}

Sofia Oliveira Correia, ${ }^{1}$ Daniel Pereira, ${ }^{2}$ Rosa Ribeiro ${ }^{2}$

\begin{abstract}
Syncope is a frequent reason for emergency room visits. In the elderly, multiple chronic conditions can difficult the diagnosis. In this case, an unexpected association between symptoms and the final diagnosis was a clinical challenge. An 80-year-old Caucasian man presents with syncopal episodes after a cough. Dizziness and visual changes were the only preceding complaints. Structured assessment is needed to face any patient, but is particularly important in the older patient because there are several constraints that hinder the approach: chronic diseases, different physiology, and clinical history sometimes more nonspecific. Thus, a diagnostic approach is discussed, with special focus in carotid sinus syndrome.
\end{abstract}

Keywords: Carotid sinus; Cough; Aged; Syncope

\section{INTRODUCTION}

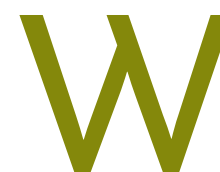

hen compared to younger patients, syncope in the elderly can be a diagnostic and therapeutic challenge. This condition is associated with higher mortality, morbidity, and impact on quality of life. In one of the largest epidemiologic studies that evaluated the incidence and prognosis of syncope, $11 \%$ who were followed for an average of 17 years as part of the Framingham Heart Study reported a syncopal episode. ${ }^{\text {The in- }}$ cidence of syncope increased with age, with a sharp rise at age 70 years. The increased risk of syncope in elderly patients appears to be due to age- and disease-related abnormalities and multiple medications, that impair the ability to respond to physiologic stresses. ${ }^{2} \mathrm{Cog}$ nitive decline also complicates many aspects of investigation and management. Diagnosis of syncope within this population requires enhanced and additional skills

1. Nephrology and Transplant Department, Centro Hospitalar do Porto, Portugal. 2. Internal Medicine, Centro Hospitalar do Porto, Portugal. due to atypical presentations, amnesia for events and the overlap with falls.

For a correct clinical approach, broad knowledge is required: from the multiple chronic conditions and the polypharmacy involved to the appreciation of the diverse clinical presentation. ${ }^{3}$

\section{METHODS}

In order to discuss the clinical approach of syncope in the elderly, we present a clinical case of an 80-yearold man, presents with syncopal episodes after a cough.

\section{CASE PRESENTATION}

The subject of this report is an 80-year-old caucasian male. He had mild aortic stenosis with no systolic dysfunction, type 2 diabetes and chronic kidney disease stage 3 .

The patient was admitted to the Emergency Department for syncopal episodes after hacking cough (four in two weeks). No other triggers were identified. The episodes were immediately preceded by dizziness and visual disturbances, without postural changes whatsoever. He recovered spontaneously. He denied any as- 
sociated chest pain, dyspnea or palpitations. No tonicclonic activity was witnessed, and he experienced no urinary or fecal incontinence.

On admission, he presented without focal neurologic findings. His heart rate was regular; blood pressure was 136/72mmHg without orthostatic changes. Thoracic and abdominal physical examination was unremarkable.

Levels of serum electrolytes, glucose, blood urea, creatinine, and complete blood counts were normal. D-dimers were normal. An electrocardiogram showed a regular rhythm consistent with sinus bradycardia (45bpm). Chest X-ray was clear with no pleural or parenchymal findings and results of a computed tomographic scan of his chest were negative for an embolic event.

Twenty-four-hour Holter ECG monitoring reveals no atrioventricular or intraventricular conduction abnormalities. A transthoracic echocardiogram revealed normal left ventricle function and no progression of his aortic stenosis ( $\max 28 \mathrm{mmHg}$ ) when compared to the last echocardiogram in 2013 ( $\max 25 \mathrm{mmHg}$ ).

In this case, there was no relation between symptoms and shaving or the use of tight collars, the only cough was admitted as a trigger.

Nevertheless, we proceeded to the carotid sinus massage (CSM), culminating in a pause for more than three seconds and syncope. The patient reports that the episode was similar to what happens spontaneously after a cough, with similar visual changes and dizziness.

He was evaluated by a cardiologist and treated with a dual-chamber (DDDR) pacemaker insertion.

Further investigation was conducted to investigate the cause of a cough. Computed tomography (CT) of the chest excluded significant pulmonary pathology. Bronchoscopy documented discrete bronchomalacia. Lung function tests documented a light restrictive and obstruction component and the patient was oriented to a pneumologist consultation.

The patient's long-term follow-up was performed and he was well for ten months after these episodes without any evidence of recurrent syncope.

\section{DISCUSSION}

We can classify syncope by the main cause: cardiac causes (arrhythmias, valvular disease); neurally me- diated (vasovagal syncope, carotid sinus syndrome, situational syncope) and orthostatic hypotension..$^{3-4}$ In general, vasovagal attacks are the most common cause of syncope, followed by cardiac etiologies.

Syncope of cardiac etiology is responsible for onethird of the cases in older population ${ }^{5-6}$ and should be promptly excluded given the high morbidity and mortality. ${ }^{5}$ The primary responsibility of the emergency clinician is to assess whether a life-threatening cause of syncope is present, and to provide appropriate management and disposition: cardiac syncope, blood loss, pulmonary embolism, and subarachnoid hemorrhage.

Therefore, we excluded the three main cardiac causes. Pulmonary thromboembolism, because there were no suggestive clinical findings and D-dimers were within the normal range; arrhythmias, with an electrocardiogram and 24-hour Holter monitoring; and significant valvular disease or left ventricular outflow obstruction with an echocardiogram.

The first diagnostic hypothesis was the progression of the previously known aortic stenosis, which is a potential cause of syncope after maneuvers such as coughing.

Orthostatic hypotension $(\mathrm{OH})$ secondary to autonomic neuropathy was ruled out because the description of the event is not compatible and objective examination was negative.

The most common cause of syncope in all age groups is the neuromediated (vasovagal, related to the situation - cough, defecation, emotion, and the carotid sinus syndrome). ${ }^{4}$ The pathophysiology of neuromediated syncope is still unclear, it is most likely due to a combination of several factors: changes in the autonomic nervous system, hormonal changes, coexistence of multiple pathologies and polypharmacy. ${ }^{3}$

Vasovagal syncope is classically preceded by prodromes (pallor, sweating, and nausea) at young age, but may not be so in the elderly. ${ }^{7}$ This cause is more common in a healthy young patient.

Carotid sinus syncope syndrome is a neuromediated subtype almost exclusive to the elderly. There is evidence that the hypersensitivity of the carotid sinus may be an epiphenomenon associated with old age and not a true disease entity. ${ }^{8-9}$ Contributing to this notion is the fact that carotid sinus hypersensitivity can be present in asymptomatic elderly. ${ }^{9}$ 
In a retrospective analysis of the case, the diagnosis could have been made sooner if the carotid sinus massage was performed earlier, this procedure is recommended for all patients with unexplained syncope over 40 years old in the absence of formal contraindications.

In previous studies, neck movements were related to carotid sinus hypersensitivity inducing hypotension. ${ }^{10}$ Therefore, given that the triggering factor in our clinical case is a cough, carotid sinus massage was performed which allowed the diagnosis, so we proceeded to pacemaker implantation. According to the most recent guidelines, treatment with proven scientific evidence (Class IIb) is the pacemaker therapy. ${ }^{11}$ In previous studies, there was a $75 \%$ reduction in the number of episodes of syncope in 5 years $^{12}$ and recurrence in $\sim 20 \%$ in 5 years. ${ }^{13}$ The decision to implant a pacemaker needs to be made in the clinical context. Prodrome and episodes occurring in typical predisposing situations for reflex syncope are predictive of post-implantation recurrence but not a positive tilt test. ${ }^{14}$ Considering these factors and the syncope low impact on overall survival, some authors defend that lifestyle counseling can be the first option when the clinical presentation is less severe. $^{15}$

A variety of disorders can be associated with cough syncope: dysfunction of the central nervous system (brain tumors, tonsil herniation, hydrocephalus, carotid arterial occlusive disease, medullary infarction); cardiovascular disorders (aortic stenosis, hypersensitive carotid sinus syndrome, cor pulmonale, constrictive pericarditis); asthma; pertussis; cystic fibrosis; traqueobroncomalacea; gastroesophageal reflux; herpetic tracheobronchitis; influenza infection; solitary fibrous tumor of the pleura. ${ }^{16}$ We also have to consider the possibility that a cough is only a co-morbidity and does not really present a causal link with the event.

As in this case, several causes can coexist: arrhythmias, vasovagal, carotid sinus hypersensitive and orthostatic hypotension, that can together contribute to episodes of syncope. ${ }^{3}$ We considered that syncope related to the situation (cough) and carotid sinus syncope syndrome can both be the main cause.

In conclusion, a structured and comprehensive assessment is needed to face this challenging diagnostic. Like many other clinical entities, syncope in the elderly needs an organized approach.

\section{CONSENT}

Written informed consent was obtained from the patient for publication of this case report and any accompanying images. A copy of the written consent is available for review by the Editor-in-Chief of this journal.

\section{REFERENCES}

1. Soteriades ES, Evans JC, Larson MG, Chen MH, Chen L, Benjamin EJ, et al. Incidence and prognosis of syncope. N Engl J Med. 2002;347(12): 878-85.

2. Lipsitz LA. Syncope in the elderly. Ann Intern Med. 1983;99(1):92-105.

3. Matthews IG, Tresham IA, Parry SW. Syncope in the older person. Card Electrophysiol Clin. 2013;5(4):457-67.

4. Parry SW, Tan MP. An approach to the evaluation and management of syncope in adults. BMJ. 2010;340:c880.

5. Marrison VK, Fletcher A, Parry SW. The older patient with syncope: practicalities and controversies. Int J Cardiol. 2012;155(1):9-13.

6. Del Rosso A, Alboni P, Brignole M, Menozzi C, Raviele A. Relation of clinical presentation of syncope to the age of patients. Am J Cardiol. 2005;96(10):1431-5.

7. Duncan GW, Tan MP, Newton JL, Reeve P, Parry SW. Vasovagal syncope in the older person: differences in presentation between older and younger patients. Age Ageing. 2010;39(4):465-70.

8. Sullivan RM, Olshansky B. Carotid sinus hypersensitivity: disease state or clinical sign of ageing? The need for hard endpoints. Europace. 2010;12(11):1516-7.

9. Kerr SR, Pearce MS, Brayne C, Davis RJ, Kenny RA. Carotid sinus hypersensitivity in asymptomatic older persons: implications for diagnosis of syncope and falls. Arch Intern Med. 2006;166(5):515-20.

10. Schoon Y, Rikkert MG, Rongen S, Lagro J, Schalk B, Claassen JA. Head turning-induced hypotension in elderly people. PLoS One. 2013;8(8):e72837.

11. Shen WK, Sheldon RS, Benditt DG, Cohen MI, Forman DE, Goldberger ZD, et al. 2017 ACC/AHA/HRS guideline for the evaluation and management of patients with syncope: a report of the American College of Cardiology/American Heart Association Task Force on Clinical Practice Guidelines and the Heart Rhythm Society. Heart Rhythm. 2017;14(8):e155-e217.

12. Brignole $M$, Menozzi $C$. The natural history of carotid sinus syncope and the effect of cardiac pacing. Europace. 2011;13(4):462-4.

13. Sutton R. Carotid sinus syndrome: progress in understanding and management. Glob Cardiol Sci Pract. 2014;2014(2):1-8.

14. Rivasi G, Solari D, Rafanelli M, Ceccofiglio A, Tesi F, Sutton R, et al. Incidence and predictors of syncope recurrence after cardiac pacing in patients with carotid sinus syndrome. Int J Cardiol. 2018;266:119-23.

15. Alboni P. Treatment of carotid sinus syncope is moving towards personalized medicine. Int J Cardiol. 2018;266:157-8.

16. Dicpinigaitis PV, Lim L, Farmakidis C. Cough syncope. Respir Med. 2014; 108(2):244-51.

\section{CONFLICTS OF INTEREST}

The authors declare that they have no competing interests. 
FUNDING

No specific funding was obtained for this study.

\section{AUTHOR'S CONTRIBUTIONS}

SC, DP, RR analyzed and interpreted the patient data and were responsible for the diagnostic assessment. SC was a major contributor in writing the manuscript. All authors read and approved the final manuscript.

\section{ENDEREÇO PARA CORRESPONDÊNCIA}

Sofia Oliveira Correia

E-mail: soacorreia@gmail.com

orcid.org/0000-0001-5025-1658

Recebido em 12-08-2016

Aceite para publicação em 29-11-2018

\section{RESUMO}

\section{ABORDAGEM INDIVIDUALIZADA E MULTIDISCIPLINAR DE UM CASO DE SÍNCOPE NO IDOSO}

Uma causa muito frequente de ida ao serviço de urgência é a síncope. No idoso, as patologias crónicas e a polimedicação dificultam a abordagem diagnóstica. No caso clínico que se apresenta a abordagem foi um desafio para a equipa médica, dada a história clínica ser tão frustre. Assim, apresenta-se o caso de um homem de 80 anos que recorre ao serviço de urgência por síncope desencadeada pela tosse. Referia apenas tonturas e alterações visuais antes da perda de consciência. É discutida a abordagem diagnóstica da síncope e os diagnósticos diferenciais, em especial a síndroma do seio carotídeo.

Palavras-chave: Seio carotídeo; Tosse; Síncope; Idoso 